\title{
Metastatic Carcinoma with Signet Ring Appearance: A Case Report Study
}

\author{
Shahin Aghaei ${ }^{1, *} ;$ Hoda Ghoreishi ${ }^{1}$ \\ ${ }^{1}$ Department of Dermatology, Shiraz University of Medical Sciences, Shiraz, IR Iran \\ ${ }^{*}$ Corresponding author: Shahin Aghaei, Shahin Aghaei, Department of Dermatology, Shiraz University of Medical Sciences, Shiraz, IR Iran. Tel.: +98-9173041694, E-mail: shahi- \\ naghaei@yahoo.com
}

Received: October 3, 2013; Revised: December 12, 2013; Accepted: January 20, 2014

Keywords:Metastatic cancer; Signet ring

\section{Case Presentation}

A 75-year-old woman presented with asymptomatic solitary infiltrative poorly differentiated nodule on her chest since four months ago. (Figure 1)

Skin biopsy from her lesion revealed many isolated malignant cells in the dermis, of which some had typical signet ring appearance. (Figures 2, and 3)

Immunohistochemical studies were negative for CD20 and CD3, and positive for Cytokeratin (Figure 4).

This poorly differentiated nodule with the specific pathology of malignant cells in the dermis with signet ring appearance is diagnostic for ring cell carcinoma. This entity may correspond to a primary or secondary tumor. In men primary tumor generally appears on the eyelid or axilla (1). Secondary tumors can originate from tumors in breast, stomatch, colon, rectum, cecal appendix, lung, bladder, prostate, endometrium and esophagus (2).

\section{Figure 1.}

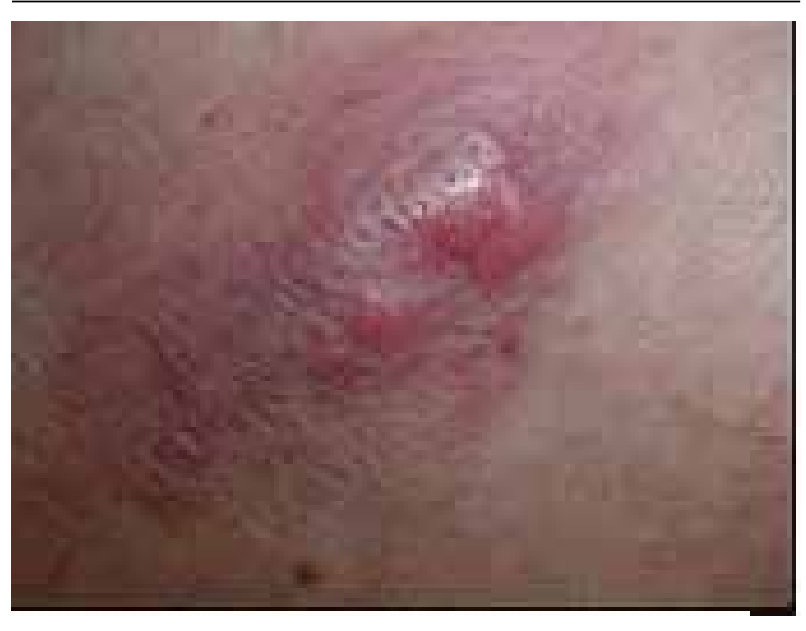

Skin biopsy from her lesion revealed many isolated malignant cells in the dermis, of which some had typical signet ring appearance.(Figures 2, and 3)

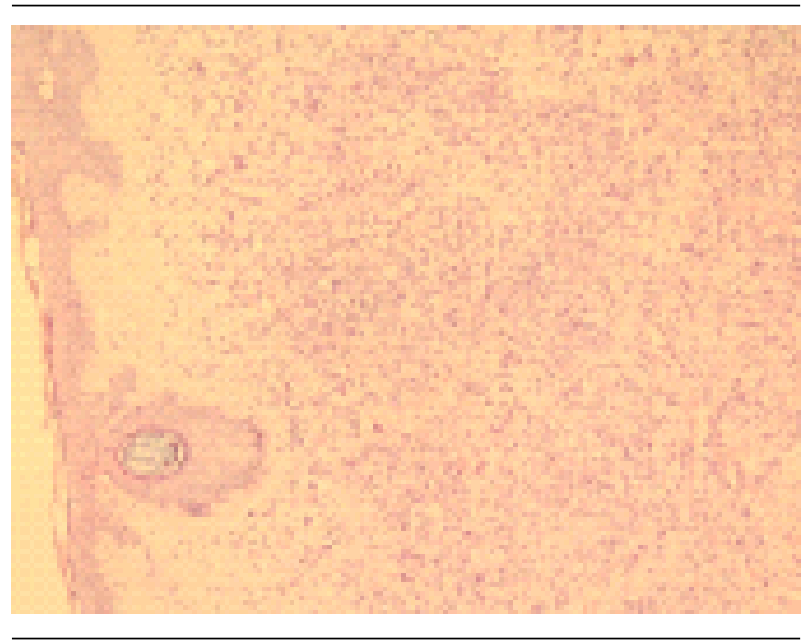

Figure 2.

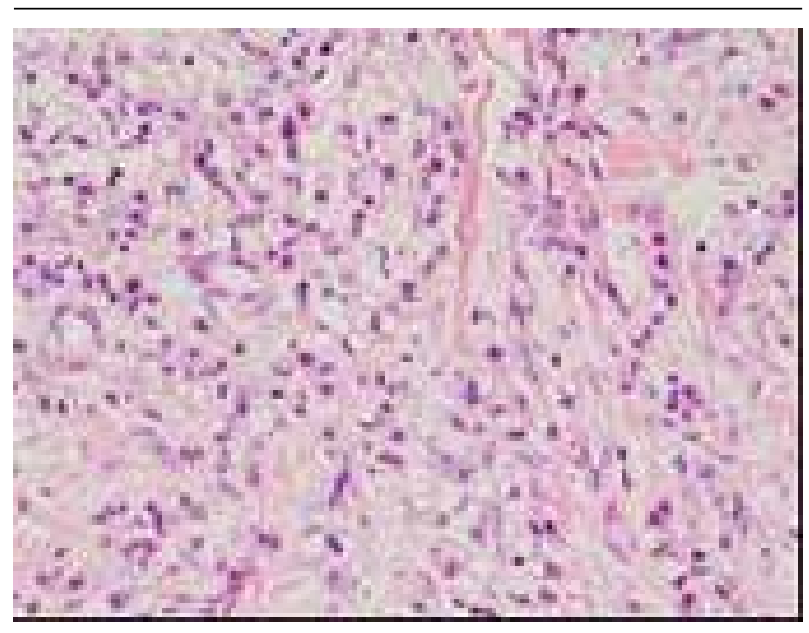

Figure 3. 


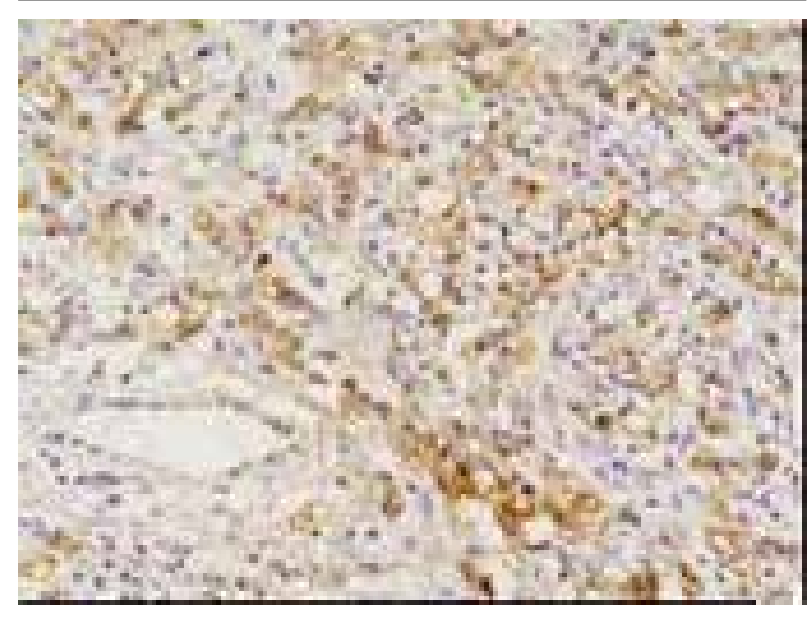

Figure 4.

The Immunohistochemical characteristics of signet ring cell carcinoma can assist the differential diagnosis between primary and secondary tumors. In our case, endoscopic biopsy from antrum mucosa revealed gastric adenocarcinoma with signet ring type. The mean survival time after the diagnosis of cutaneous metastasis is 7.5 to 34 months (3).

\section{Acknowledgements}

There is no acknowledgement.

\section{Financial Disclosure}

There is no conflict of interest.

\section{References}

1. Gonzalez-Lois C, Rodriguez-Peralto JL, Serrano-Pardo R, Martinez-Gonzalez MA, Lopez-Rios F. Cutaneous signet ring cell carcinoma: a report of a case and review of the literature. Am J Dermatopathol. 2001;23(4):325-8.

2. Aneiros-Fernandez J, Husein-ElAhmed H, Arias-Santiago S, Escobar Gomez-Villalva F, Nicolae A, O'Valle Ravassa F, et al. Cutaneous metastasis as first clinical manifestation of signet ring cell gastric carcinoma. Dermatol Online J. 2010;16(3):9.

3. Saeed S, Keehn CA, Morgan MB. Cutaneous metastasis: a clinical, pathological, and immunohistochemical appraisal. J Cutan Pathol. 2004;31(6):419-30. 